\title{
3D VISUALIZATION OF CULTURAL HERITAGE ARTEFACTS WITH VIRTUAL REALITY DEVICES
}

\author{
S. Gonizzi Barsanti a, *, G. Caruso a , L. L. Micoli a , M. Covarrubias Rodriguez a , G. Guidi a, \\ ${ }^{a}$ Department of Mechanical Engineering - Politecnico di Milano, Italy - (sara.gonizzi, giandomenico.caruso, laura.micoli, \\ mario.covarrubias, gabriele.guidi)@polimi.it
}

KEYWORDS: Cultural Heritage, Virtual Reality, Oculus Rift, Leap Motion, Unity, 3D modelling, Visualisation

\begin{abstract}
:
Although 3D models are useful to preserve the information about historical artefacts, the potential of these digital contents are not fully accomplished until they are not used to interactively communicate their significance to non-specialists. Starting from this consideration, a new way to provide museum visitors with more information was investigated. The research is aimed at valorising and making more accessible the Egyptian funeral objects exhibited in the Sforza Castle in Milan. The results of the research will be used for the renewal of the current exhibition, at the Archaeological Museum in Milan, by making it more attractive. A 3D virtual interactive scenario regarding the "path of the dead", an important ritual in ancient Egypt, was realized to augment the experience and the comprehension of the public through interactivity. Four important artefacts were considered for this scope: two ushabty, a wooden sarcophagus and a heart scarab. The scenario was realized by integrating low-cost Virtual Reality technologies, as the Oculus Rift DK2 and the Leap Motion controller, and implementing a specific software by using Unity. The 3D models were implemented by adding responsive points of interest in relation to important symbols or features of the artefact. This allows highlighting single parts of the artefact in order to better identify the hieroglyphs and provide their translation. The paper describes the process for optimizing the 3D models, the implementation of the interactive scenario and the results of some test that have been carried out in the lab.
\end{abstract}

\section{INTRODUCTION}

Reverse Engineering (RE) and Computer Graphics (CG) are well-known techniques for analysing, studying, preserving and visualizing Cultural Heritage $(\mathrm{CH})$ assets. The Politecnico di Milano unit took part to the 3D Icons project (http://3diconsproject.eu/), funded under the European Commission's ICT Policy Support Programme and aiming to increase the 3D content available to Europeana's users. Within this project, the unit was responsible of the 3D digitization work package and dealt with several historical artefacts including those held in the Archaeological Museum and in the Sforza Castle in Milan. The objects belonged to different historical periods, Egyptian, Etruscan, Greek, Roman, Medieval and of the Renaissance. They were surveyed using photogrammetry and processed with a Structure from Motion (SfM) software. The final 3D models were then edited in order to be viewable and downloadable as 3D pdf through the internet to allow the visualization by using also low-end computer. As a step forward in this visualization process, it was decided, in agreement with the curators of the Archaeological Museum, to take advantage of the 3D models by creating a new way to provide the museum visitors with more information about them. In particular, the aim was to exploit the full potential of the digital contents to communicate the significance of the historical artefact to non-CH specialists.

The work focuses on the 3D models of the ancient Egyptian funeral objects because there is the plan of a complete restoration of the exhibition in the Sforza Castle. The first part of the research involves the better understanding of the Egypt objects modelled and of the language of the ancient Egyptians, the hieroglyphics. Four important and interesting artefacts were considered for this scope: two ushabty (figurine placed in tombs intended to act as servants for the deceased, should he/she be called upon to do manual labour in the afterlife), a wooden sarcophagus and a heart scarab, that had become, by the early New Kingdom, part of amulets protecting mummies.

The idea is to enhance the understanding of these Egypt artefacts, starting to the comprehension of the objects, its meaning and the language of the ancient Egyptians. The plan, in the future, is to produce a $3 \mathrm{D}$ virtual interactive tour regarding the "path of the dead", a very important ritual in the ancient Egypt, to complement and augment the experience and the comprehension of the public through interactivity. 3D virtual environments, in fact, can be a proper instrument for giving context to pieces of information, since they are attractive and accessible for the visitors of a museum. In particular, the 3D models were implemented with a description of the object and some point of interest that provides specific information about interesting symbols or feature. The attention is by now pointed to the possibility to select the symbols of the hieroglyphs that, combined together, arrange single words in the text: the symbols are virtually widened in the 3D space in order to better identify the hieroglyphs, and then translated. As some words, as in for example the name of the deceased and his family, are repeated in the script, the user has, in this way, the ability to recognize the symbols that compose the names in the full text. There are also some descriptions to explain some particular images or drawings on the objects.

To make the interaction with the so-implemented 3D models more engaging, Virtual Reality (VR) technologies were used. An immersive and interactive VR scenario has been implemented with low-cost devices, for visualisation and interaction, integrated by using a development platform for video games.

The paper describes the process for optimizing of the 3D models, the implementation of the interactive scenario and some preliminary test that have been carried out involving students and researchers as test users. The project is still ongoing and the

\footnotetext{
* Corresponding author.
} 
results presented in this paper are the first step to a complete implementation and real installation in the Museum.

\section{VR APPLICATION TO CULTURAL EXHIBITIONS}

As highlighted in [El-Razaz, 2007] VR is surely a valid tool to interact with 3D models and a fundamental help in making culture more accessible to the wide public and in documenting, recording and conservation of the Cultural Heritage. VR can help the museum curator to adapt the cultural proposal and the information about the artefacts based on the different type of visitor's categories [Reffat et al, 2013]. A Virtual and interactive exhibition can be entirely built by using dedicated authoring software, as described in [Rafal et al.] and then the contents can be shared through internet or using touch-screen displays within the real museum.

Thanks to the flexibility provided by virtual exhibitions, a museum curator can implement them in several ways. As proposed in [Pescarin, 2014], eight discriminant elements can differentiate virtual exhibitions. These elements are: content, interaction, duration, communication, level of immersion, distribution, scope and sustainability. Interaction and level of immersion are the surely the elements that are deeply influenced by the VR technologies chosen for the exhibition.

The interaction is the way through which users can manage the exhibition contents [Roussou et al., 2015; Vayanu et al., 2012 ]. VR interaction technologies and techniques used in $\mathrm{CH}$ are different and always include the use of devices that are able to convey the user's intents to the digital contents. In the past, typical interaction devices were joysticks, mice, keyboards while, nowadays, the trend is to use more engaging and natural ways to interact with the digital contents. Gesture-based is surely the interaction technique that provides more benefits during a virtual exhibition: users can directly interact with digital contents through the movements of their hands (or body) without wearing or touching any device.

An application example of gesture-based interaction in $\mathrm{CH}$ is the Etruscanning Project [Pietroni et al., 2012] where the virtual environment allows users to walk in and interact with the artefacts by using their gestures. Another example is the QueryArch3D [Richards-Rissetto et al., 2012] that is an online tool enabling users to move and query multiple-resolution 3D models through the movements of their body. Finally, in [Cirilli, 2013] the users can interact with the history of the freeze of the Trajan Column through the movements to their hands. The visitors can leaf through the unrolled basrelief of the column, zoom in and zoom out and also activate and press different points of interest that explain simple parts of the story narrated by the sculpted column.

Conversely, the level of immersion of a virtual exhibition is influenced by the technology used to display digital contents. In [Carrozzino, Bergamasco, 2010], is well discussed how the level of immersion is linked to the display systems. In particular, external display systems, such as Power Wall and CAVE [Cruz-Neira, et al. 1992; Lee et al, 2010], provide the highest level of immersion [Gutierrez et al., 2004; Hirose, 2006]. Unfortunately, one of the most crucial and problematic factor of these visualization system is the high cost of the equipment and of the installation. In addition, these display systems are typically stationary, require a lot of space and controlled environment conditions. In [Bruno et al., 2010] the authors proposed a low-cost multimedia stereoscopic system called MNEME, which allows the user to interact in a free and easy way with a rich collection of archaeological finds. However, required budget (the authors claim 15,000€) and space to mount the structure could be still not accessible to many museums.

The Head-Mounted Displays (HMDs), instead, could represent a good compromise between costs and level of immersion. Besides, the users' feeling of immersion and interaction is widened and the setups are more manageable [Loizides et al. 2014].

Starting from these considerations, an optimal hardware configuration, which provides a good interaction and a good level of immersion for a VR environment for $\mathrm{CH}$, has to include low-costs HMD and a gesture-tracking device. In [Webel et al. 2013] the author use the HMD Oculus Rift and the hand tracker Leap Motion to create two different kind of immersive reality, implementing two different kind of navigation. The cost of these two devices is quite affordable (440 USD, equivalent less than $400 €$ ) and they can be used to generate easy and flexible setups. By taking into account this experience, this research proposes to implement the VR environment by coupling the Oculus Rift and the Leap Motion to make attractive and interactive the virtual exhibition of unique Egyptians artefacts stored in the Sforza Castle.

\section{TEST OBJECTS}

The VR scenario developed in this research focused on artefacts of the funerary tradition in ancient Egypt. For ancient Egyptians the thought that death, as an end, does not exist and it was rejected because was intended only as a modification of the vital harmony.

The ancient Egyptian language belongs to the family of Semitic languages and knows a history that runs through the entire Egyptian civilization from the mid-third millennium BC until the fifth century AD. It survived much longer in its last linguistics phase, the Coptic, the language of the Christian church of Egypt, usually but not always the Egyptian language in Greek characters. For most of its history, the ancient Egyptian is characterized by the use of two basic writing systems: the hieroglyphic system, or a system of pictorial signs, and its cursive form, the hieratic. These two types of writing are mutually concurrent between the mid-third millennium BC and the fourth century AD: while the hieratic disappears during the third century $\mathrm{AD}$, the last hieroglyphic inscription known today was found in File and is dated to $394 \mathrm{AD}$.

In general, the hieroglyphic system is the one most commonly used in monumental and funerary inscriptions, while the hieratic in documentaries texts (but this distinction is never so clear). The hieroglyph system consists of a large number of signs (from about 800 in the classical stage of the language to a few thousand in later periods), which are divided into two main categories: ideograms and phonograms. The first show what they represent pictographically, the latter - which are the majority of the signs of the system itself - have phonetic value, which is always consonantal. The Egyptian (like other Semitic languages) does not record in writing the vowels and to be able to read in our modern languages such sequences of consonants, an "e" is inserted. Some phonograms has the value of a single consonant, but most of them has the value of two or even three consonants. Some signs have the value as of phonograms and as ideograms, while others are 'mute' and serve only to indicate the relevance of the words to a specific semantic boundary.

For this project four-test objects that are significant both for historical and archaeological reasons, have been used. 


\subsection{Ushabty}

Funerary statuettes put in the tomb of the deceased, varying in number from a few to hundreds.

They usually have the shape of a mummy and usually hold agricultural hand tools: a hand hoe, a pickaxe, a bag for the seeds (which they carry on their shoulders and is only visible on the back of the statues). Their task was to replace the deceased of any class - if it had been called to work in the fields of Ialu, or agricultural fields of Osiris in the afterlife, as indicates the formula of the Book of the Dead who often engraved extensively on their body.

The first object is a fragment of an ushabty (Figure 1) belonged to Pharaoh Akhenaten (ca. 1353-1336 BC), born under the name of Amenhotep (IV), the youngest son of one of the most important ruler of the XVIII dynasty, Amenhotep III, and his heir to the throne. He is amongst the most renewed Egyptian rulers and his name is mostly linked to a religious reform he made in the direction of a monotheism. In fact, early in his reign he focused on the sole cult of the solar deity in the aniconic form of the solar disc (previously Ra-Atum, who was called only as the 'Aten' - the disc), abolishing the animal and even the anthropological forms of the deity. The dimensions of the fragment are $6 \times 4.3 \times 6.4 \mathrm{~cm}$.

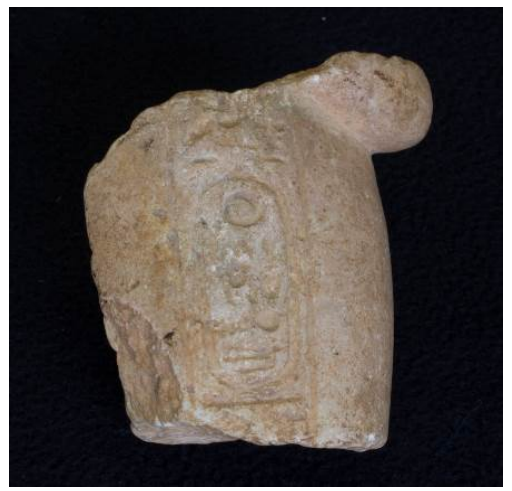

Figure 1 . The fragment of the ushabty belonged to pharaoh Ahkenaten

The second belonged to Imenmes, (Figure 2) worker of the Deir el-Medina (west Thebes) community and minister. On the body of the statue is painted the formula nr. 6 of the Book of the Dead, with the invocation to the ushabty for it to answer the call in the fields of Ialu, for Osiris (title of the deceased) Imenmes. The ushabty is $33.5 \mathrm{~cm}$ high.

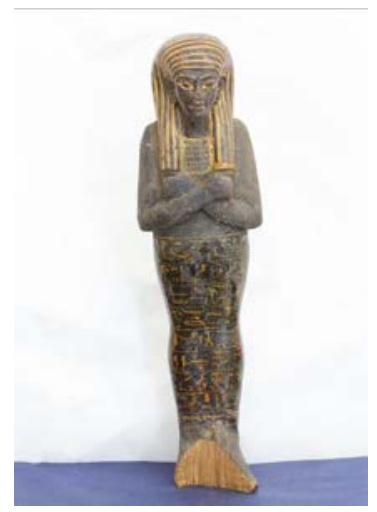

Figure 2. The wooden ushabty of the minister Imenmes with the written part depicted on the body of the mummy

\subsection{Heart Scarab}

The so-called heart scarab (Figure 3) (VII-IV sec. a.C.) is the most important funerary amulet: its name derives from its position on the mummy - it was placed over the mummy's heart (over or between the mummy bandages). It is quite often inscribed with the spell 30B of the Book of Going forth by Day (alias Book of the Dead), the compilation of magical/ritual spells which accompanies the dead in his/her voyage into the Afterlife.

Many spells in the Book of the Dead gave the dead person power to control the elements of their personality and the forces of nature. Spells prevented the decay of the body and the loss of the most essential parts - the head (the location of the identity and senses) and the heart (the location of the mind). Other spells sustained the non-physical parts of the person, the shadow, name and the ka and ba spirits. Some spells enabled the dead person to breathe, drink, control fire, freely move and travel in the sun god's boat. One of the most important set of texts were 'transformation spells', allowing the dead person to turn into different forms such as a falcon, a heron, a swallow, a lotus flower, a snake or a crocodile. These forms gave the deceased free movement and special divine powers. Specifically, the spell 30B binds the deceased's heart to not witness against the dead while it is weighed on the scales in the judgment before the divine tribunal presided by Osiris. This God is in charge to proclaim the dead —after his/her 'confession'- "true of voice” and so in the worthiness to reach his/her final goal: the lands of Osiris, the Egyptian version of the Paradise. It was believed that upon death, ones fate in the afterlife was determined by the weighing of his/her's heart. The heart was kept within the body during mummification so that it can travel with the deceased into the afterlife. The dead entered the underworld (Duat), where Anubis, the God of the afterlife, weighed the person heart on a scale against the feather of Ma'at, the goddess of order, truth, and righteousness. If the heart weighed more than the feather, meaning that the person was more wicked than good, then the heart would be devoured by Ammut, a demon with the head of a crocodile, the front half of the body of a leopard, and the back half of a hippopotamus. If a person's heart was devoured by Ammut, than he would die a second death and be completely annihilated from existence. The dimensions of the heart scarab are $5.5 \times 7.4 \mathrm{~cm}$.
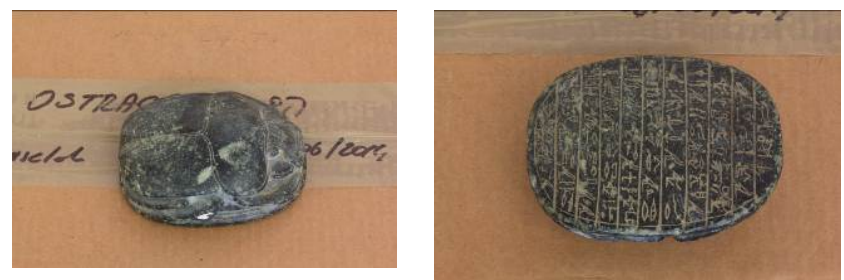

Figure 3. The heart scarab with the spell 30B of the Book of the Dead written of the lower part.

\subsection{Wooden sarcophagus}

It belonged to P(a)f-tjau-auy-aset (VII sec. a.C.). The interior is anepigraphic. On the exterior, the long sides (one incomplete) and one short (also incomplete) are decorated with two registers involving a theory of gods and demons, accompanied by brief captions identifying: a continuous band of hieroglyphic text close to the top edge, contains the name of the deceased, the matronymic and patronymic and a prayer of invocation to the gods funeral. On the second short side (at the head of the 
deceased) is an image of the goddess Nephthys surrounded by a text that shows the name of the deceased and a promise of protection of the goddess (Figure 4). The dimensions of the sarcophagus are $200 \times 65 \times 40 \mathrm{~cm}$.

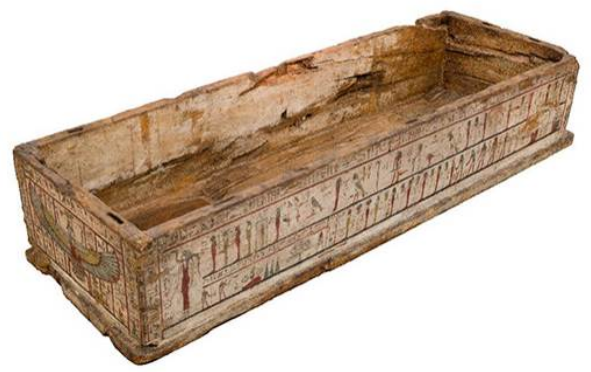

Figure 4. The wooden sarcophagus depicted.

\section{DESCRIPTION OF THE IMPLEMENTED VR SCENARIO}

As previously said, the idea is to enhance the understanding of the Egyptian funerary objects, which has been described in the previous section, by proposing an interactive translation of the Egyptian language. The idea has been developed by creating a VR scenario that mainly includes these three elements:

- $\quad 3 D$ models;

- $\quad$ VR devices;

- Software application.

The 3D models selected as test objects for this research are part of a wider set of archaeological artefacts stored in the Archaeological Museum of Milan and in the Sforza castle and were chosen for their importance and uniqueness. The objects were surveyed and modeled for the 3D Icons project, with the final goal of sharing and visualizing them on the internet. It was decided to use photogrammetry to survey them because of the shape and the texture of the artefacts (more cooperative with passive devices instead of active ones) and because with this technology less time is needed in processing the models.

The VR devices used to implement the VR scenario are Oculus Rift DK2 (https://www.oculus.com/) and the Leap Motion (https://www.leapmotion.com/). The Oculus Rift DK2 is a 3D Headset coupled with an inertial and optical tracking system that was used to provide a three-dimensional, immersive and interactive visualization of the 3D model. The Leap Motion, instead, is an optical hands tracker that was used to allow the users to interact with the 3D models directly by using his hands. The Leap Motion was mounted on the top of the Oculus Rift DK2 and, thanks to its wider field of view (Figure5); the hands are always tracked wherever the user is looking at.

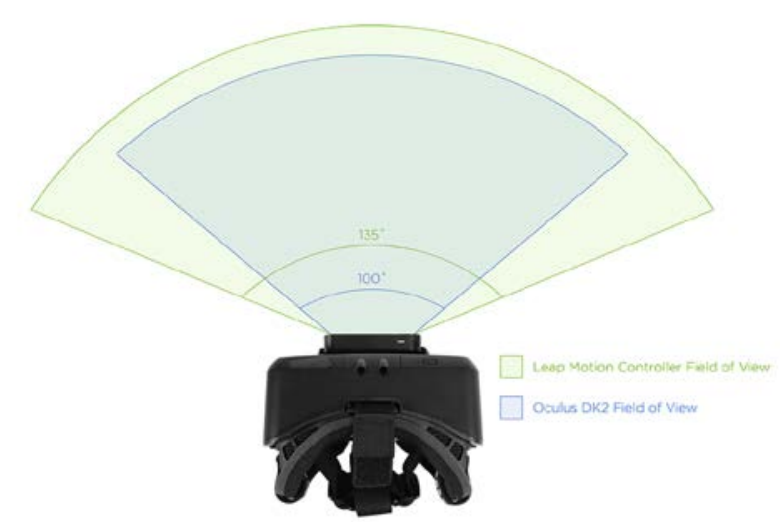

Figure 5. The comparison between Oculus and Leap Motion filed of view (blog.leapmotion.com)

The software application, managing the VR devices, was implemented by using Unity (http://unity3d.com/). Unity is a game development platform and real-time rendering engine widely used in several fields to develop 3D applications and interactive VR environments. Its features allowed managing the stereoscopic visualization of the aforementioned Egyptian 3D models and implementing the interactive scenario of the VR scenario. As some words are repeated in the script, like for example the name of the deceased and his family, thanks to this interface the user has the ability to recognize the symbols that compose the names in the full text. There are also some descriptions to explain some particular images or drawings on the objects. More information about the implementation of the VR scenario is provided in the following paragraphs.

\subsection{D models: generation and post processing}

The test objects were surveyed trough photogrammetry using a tripod and moving the camera all around the objects. Two different cameras were used, a mirrorless Sony Nex 6 coupled with a $24 \mathrm{~mm}$ lens for the sarcophagus while a APS-C Canon $60 \mathrm{D}$ coupled with a $60 \mathrm{~mm}$ macro lens was used for the three other objects. The GSDs obtained were $0.39 \mathrm{~mm}$ for the sarcophagus and $0.14 \mathrm{~mm}$ for the two ushabty and the scarab.

The 3D models were obtained using a commercial software, Agisoft Photoscan (www.agisoft.com), and the main purpose was to have models accessible online, for pure visualization. The pipeline of the photogrammetric process was clearly outlined in order to have accurate models in a shorter period, as the models were produced for a European project and the goal of the unit was to model 527 artefacts in total [Guidi et al., 2014]. Taking into account the purpose of the models, the high resolution 3D models were modelled putting as a maximum limit of triangles for the final mesh 2,000,000. This size was decided considering the average shape and dimension of the artefacts to be modelled and was stated to be ideal for the purpose of the project. The high-resolution models obtained through the photogrammetric pipeline were decimated and reduced in order to have lighter models with a high-resolution texture. The models were simplified in Polyworks with a function that keep simplifying the model as the difference between the simplified and the original is less than a fixed threshold, that can be set half the intrinsic uncertainty of the photogrammetric process (e.g. if the photogrammetric accuracy is 0.84 the decimation parameter will be 0.42 ). The specifics of each 3D model are summarized in Table 1 


\begin{tabular}{|r|c|c|c|c|}
\hline & $\begin{array}{c}\text { Ushabty } \\
\text { Akhenaten }\end{array}$ & $\begin{array}{c}\text { Usbaty } \\
\text { Imenmes }\end{array}$ & $\begin{array}{c}\text { Heart } \\
\text { Scarab }\end{array}$ & $\begin{array}{c}\text { Wooden } \\
\text { Sarcophagus }\end{array}$ \\
\hline Size [cm] & $6 \times 4.3 \times 6.4$ & 33.5 (height) & $5.5 \times 7.4$ & $200 \times 65 \times 40$ \\
\hline $\begin{array}{r}\text { High-res } \\
\text { file size }\end{array}$ & $200 \mathrm{MB}$ & $211 \mathrm{MB}$ & $210 \mathrm{MB}$ & $153 \mathrm{MB}$ \\
\hline $\begin{array}{r}\text { Low-res } \\
\text { file size }\end{array}$ & $15.5 \mathrm{MB}$ & $36.7 \mathrm{MB}$ & $29 \mathrm{MB}$ & $2.8 \mathrm{MB}$ \\
\hline $\begin{array}{r}\text { High-res } \\
\text { Model } \\
\text { polygons }\end{array}$ & $1,912,726$ & $2,000,000$ & $2,000,000$ & $1,457,664$ \\
\hline $\begin{array}{r}\text { Low-res } \\
\text { Model } \\
\text { polygons }\end{array}$ & 116,452 & 251,274 & 237,892 & 31,006 \\
\hline $\begin{array}{r}\text { Texture } \\
\text { size }\end{array}$ & $4096 \times 4096$ & $4096 \times 4096$ & $4096 \times 4096$ & $4096 \times 4096$ \\
\hline
\end{tabular}

Table 1. Differences between the high and low-resolution 3D models of each artefact.

The texture connected to the obj file was created using the "mosaic" blending mode function in Photoscan and the final file was a jpg. To highlight the words that was decided to translate, using the procedure explained in the previous paragraph, the texture of each models was duplicated so that each texture was associated to a single word. The single file was imported in Photoshop and the word identified was then outlined manually with different colours. This part was easy taking into account that the texture is visible in one single jpg file, but, due to the mosaic-blending mode, outlining the single drawings composing the words was difficult. It happened that a part of the word to be outlined was visible in a portion of the texture and the other sometimes on the opposite side of the file (Figure $6)$.

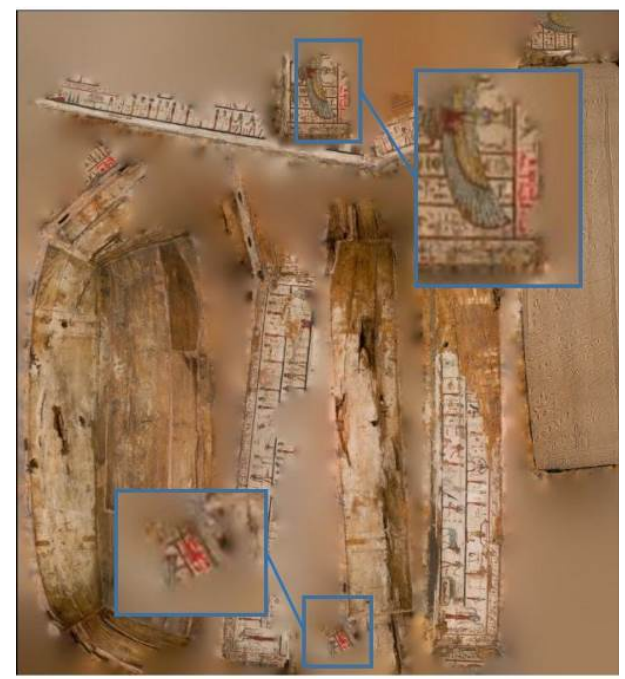

Figure 6. The difficulties in outlining the words in the texture of the objects because of the mosaic blending.

\subsection{VR devices integration}

The latest and newest virtual reality technologies have been used for this project, the Oculus Rift Development Kit 2 (DK2) integrated with the Leap Motion.

The Oculus Rift DK2 Rift is a virtual reality head-mounted display featuring a resolution of $960 \times 1080$ per eye, low- persistence AMOLED display designed to use low-persistenceof-vision to smooth motion, as well as a full positional tracking system (tab. 2). The DK2 uses an optical camera based tracking system which together with the on board IMU provides the ability to track rotational and translational movement using on board IR LEDs which sit behind an IR transparent shell on the front and sides of the DK2. This means that (within the camera's field of view) the system knows where the head is in 3D space. It is possible to move the head up and down, downwards and backwards relative to the camera and a DK2 compatible application can adjust the view appropriately, allowing leaning in and out of a scene or lean left and right.

\begin{tabular}{|l|c|}
\hline Sensors & $\begin{array}{c}\text { Accelerometer, Gyroscope, } \\
\text { Magnetometer }\end{array}$ \\
\hline Inertial update rate & $1000 \mathrm{~Hz}$ \\
\hline Positional update rate & $60 \mathrm{~Hz}$ \\
\hline Field of view & $100^{\circ}$ \\
\hline Video & HDMI \\
\hline
\end{tabular}

Table 2. The specifics of the Oculus DK2

(http://digitalchumps.com/gamingnews/318- latest-news/oculusrift-announces-development-kit-2.html)

The Leap Motion senses how the hands naturally move and permits to point, wave, reach, grab objects in the virtual environment. The heart of the device consists of two cameras and three infrared LEDs. These track infrared light with a wavelength of 850 nanometers, which is outside the visible light spectrum. Thanks to its wide-angle lenses (Figure 6), the device has a large interaction space of eight cubic feet, which takes the shape of an inverted pyramid - the intersection of the binocular cameras' fields of view. The Leap Motion Controller's viewing range is limited to roughly $60 \mathrm{~cm}$ above the device, limited by LED light propagation through space, since it becomes much harder to infer the hand's position in 3D beyond a certain distance. LED light intensity is ultimately limited by the maximum current that can be drawn over the USB connection. At this point, the device's USB controller reads the sensor data into its own local memory and performs any necessary resolution adjustments. This data is then streamed via USB to the Leap Motion tracking software. The data takes the form of a grayscale stereo image of the near-infrared light spectrum, separated into the left and right cameras. Typically, the only objects you seen are those directly illuminated by the Leap Motion Controller's LEDs. The Leap Motion Application Programming Interface (API) includes also an effective skeletal tracking model that provides additional information about hands and fingers and improves the overall tracking data. In this way, the user is able to move the object and select the part of interest, even if the two hands are not completely tracked.

The Oculus DK2 coupled with the Leap Motion (Figure 7) were used to allow users playing, grabbing, moving and rotating the 3D models in the VR scenario. In addition, users can select the description of the objects and highlight the words of interest in order to enhance them and to get the transliteration (from the images to the letters) and the translation. 


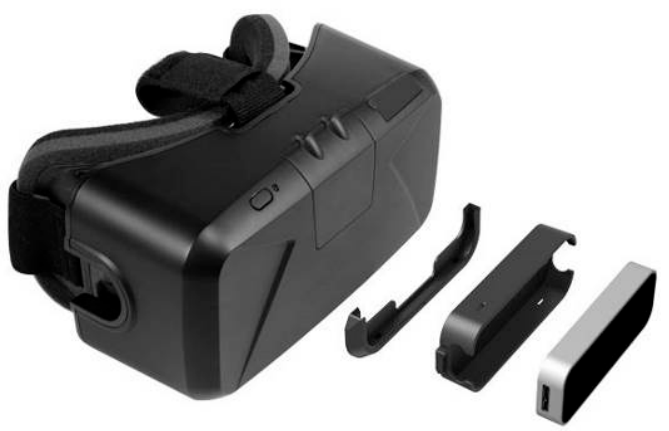

Figure 7. Oculus with Leap Motion (www.leapmotion.com)

\subsection{Software application}

The software application of the VR scenario has been developed by using Unity 5.0, a cross-platform game engine used to develop video games for PC, consoles, mobile devices and web sites. Unity 5.0 was released free on March 3, 2015, adding the real-time global illumination based on the Geomerics Enlighten technology, physically based shaders, HDR skyboxes, reflection probes, a new audio mixer with effects and enhanced animator workflows.

The software application was implemented by importing in Unity the low-resolution obj files, described in section 4.1, with their own texture. Import of 3D models is easily done and they can be correctly visualised within Unity just by adding some virtual lights. However, since the purpose of the project was to highlight single words or part of the $3 \mathrm{D}$ models to make the hieroglyphs more understandable, such models have to be further elaborate by using 3D Studio Max (http://www.autodesk.it/products/3ds-max/overview), which is a 3D computer-graphics software. The parts including the points of interest were isolated and cut being careful not to change the orientation of the main model and the pieces cut. These parts of the model was exported in .fbx using as constrains meter as units (because Photoscan works in meter) and "axis conversion" as $\mathrm{Y}$ axis- up. The cut parts were then imported in Unity in order to have collider objects useful for the selection and the enhancement of the parts with the words with the hand avatars. To avoid any gender or race discrimination, robotic avatars have been selected.

Then, some scripts were implemented to enable the user to interact with the 3D models. The scripts allow user to rotate and grab it to see the 3D models in different position by using the movements of their hands, as shown in Figure 8 (a), (b).

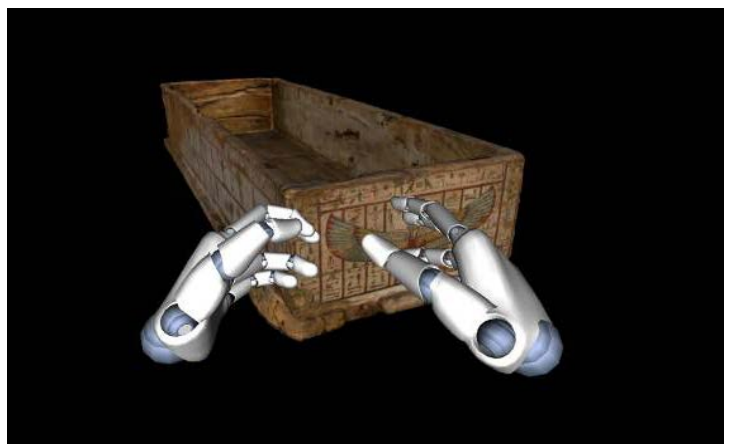

(a)
While passing over with the hands-avatar, parts of the text visible on the model are highlighted and/or magnified. If user wants to know more about these words she/he can touch the part, the word is automatically enhanced and the transliteration and the following translation appears, as shown in Figure 9 (a) (b), (c). In this way, any word, important for the interpretation of the object, can be easily identified on the 3D shape of the model and, after been selected using the possibility of "seeing" the hands with the Leap Motion, a transliteration and a translation of the word can be displayed to comprehend its meaning.

The translation of the words follows several steps: first, a transliteration of the signs has to be done, from the drawings to "our" alphabet inserting a mute "e" because the ancient Egyptian alphabet did not have vowels. The way the translation goes, first with the transliteration of the signs adding vowels and then the translation and all the passages from transliteration and translation (fundamental for the hieroglyphs) is given by the following example:

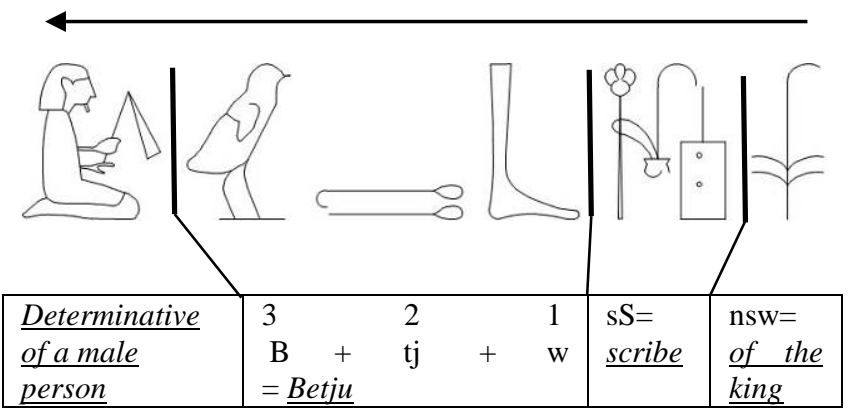

The word has to be read from right to left and the translation is "the royal scribe Betju".

The software application includes a starting page with a brief description on how the environment works and about the movements and the commands to navigate it. Then the user can select the intro page with a brief description of ancient Egypt (history, culture) and its language.

A window is also visible on the side of the screen permitting the selection of the different models, so the user can decide which object to start with. Selecting the model, this is visible in the main screen with a description of it. During the virtual navigation, it is possible to highlight the interesting words and to select them in order to have the transliteration (with a brief description of the identification of ideograms and phonograms) and the translation of them.

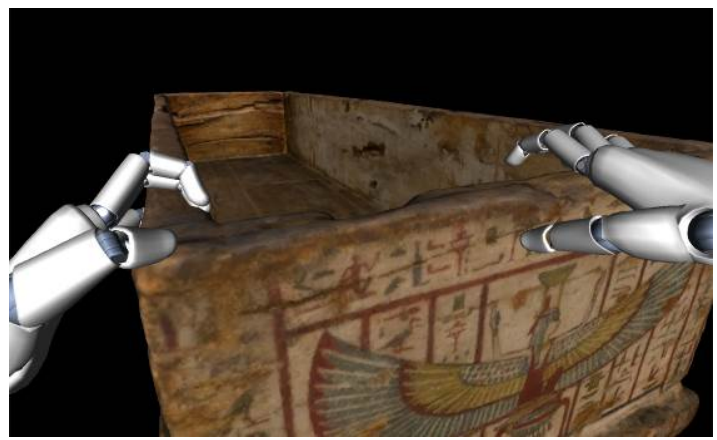

(b)

Figure 8. Some pictures of the implemented VR scenario: (a) (b) the grabbing and rotating of the object with the possibility of enlarging it. 


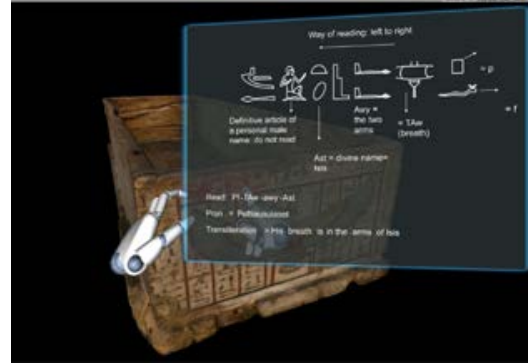

(a)

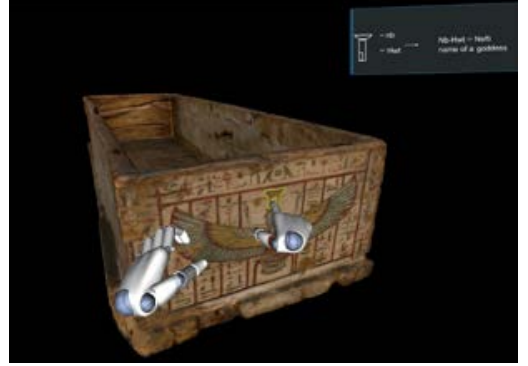

(b)

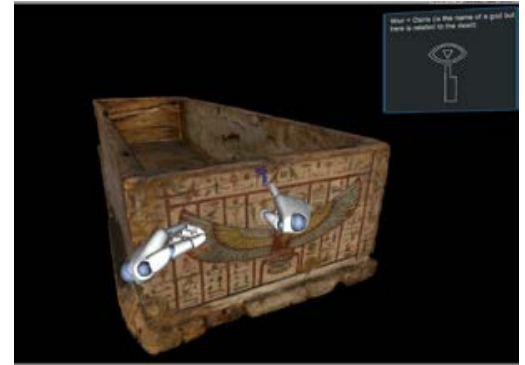

(c)

Figure 9. Some pictures of the implemented VR scenario: (a) the highlighting and translation of the name of the deceased (b) ) the highlighting and translation of the name of the Goddess Nefti (c) the highlighting and translation of the name of the God Osiris, related to the dead.

\section{DISCUSSION AND FUTURE WORK}

Some tests have been carried out in the Politecnico of Milan labs using students and researchers as test users. No one who have tried the prototype had problems in understanding the control and the passages through the virtual environment. The possibility of virtually touching the models and the navigation through them was one of the first positive elements of the project, while the description of the hieroglyphs, the procedure that is behind the translation and the understanding of them has aroused a great interest, especially with the connection with the real translation of some words. Some of the test users have tried a slight feeling of nausea after a prolonged use of the system Oculus + Leap Motion. This is a well-known effect of the stereoscopic visualization provided by the Oculus. Mainly it depends on the high latency and the low resolution of the display. The low resolution negatively affect the texts visualization. During the first tests, the words were difficult to be read since they were blurry and and therefore not understandable. The problem was solved using widgets as a pop up window. With this widget modality, it is possible to insert the text using a bigger font with a colour that was in high contrast with the background. While all these passages help a lot in making the texts more readable, it is clear that the limitations of the visualization system do not allow obtaining a perfect readability of the text. However, we reckon these issues will be overcome in the future by the new releases of the Oculus.

As future work, there is the plan to implement the system creating a virtual "path of the dead". Many rituals were followed to prepare the dead to his last journey, as maps to indicate which way to follow put inside the tomb, a book to indicate which risks the soul could meet and another one filled with formulas and magical rites to protect the soul. Many were the risks that await the adept on the roads of the other world, populated by genes: to pass, the traveller must convince the guards to let him go ahead because he was worthy and had the knowledge, using the magical powers acquired thanks to funeral rites. The deceased, in spirit form, had to journey through the world of the dead. The netherworld was thought to be beneath the earth (occasionally it was considered to be in the sky). Known as the Duat, it was regarded as a mysterious place, and was never mapped or described in a consistent manner. The dead person could travel on foot, by boat or through the air, in different physical forms. The Book of the Dead contained information about features and beings in the netherworld including gateways, caverns and mounds, watched over by strange gods who had to be pacified. Safe passage could only be guaranteed with the sacred knowledge contained in the spells. The idea is to translate this journey in a virtual tour using the artefacts modelled as accessories to the story and as elements that can explain the different part of the path. Their purpose in afterlife and the reason why they were put in the tomb with the deceased could be used as a virtual window to the different part of the path, where the artefacts would have been eventually used. The rituals during the burial, the formulas given to the dead, everything will be explained and connected to the artefacts or explained through them.

\section{CONCLUSION}

As delegate institutions interested in the research and exhibition of art, culture and education, museums are one of the first organization to make use of advanced VR technologies to investigate their educational potential determining how they provide public education and amusement. These technologies allow visitors to travel through space and time without walking out of the museum (immersive experience) and have a great educative function permitting to explain in an easy and attractive way information and concepts that could prove to be complicated. The combination of information and images that can be interactively manipulated by the user and the immersive experience are two basic advantages of VR technologies: the user can both experience the sensation of being in an ancient world and can actively participate in the virtual environment.

While programming and developing a VR hub to make available more information and to enhance the cultural offer of a museum, two fundamental points have to be considered, economic (museums usually do not have the possibility to invest in expensive installations) and practical (the lack of space).

Both the problems can be easily overcame thanks to the availability of low-cost, small and light devices, that can be combined in order to produce a simple to use, friendly and realistic application.

For this research, it was decided to use and test the Oculus DK2 and Leap Motion Controller combined together because they offer a natural level of immersion to interact with the digital contents.

The project is still ongoing; the future works involve the creation of a virtual environment regarding the "path of the dead" where the models of the objects already processed will be inserted, integrated with other models. The level of information provided will be increased with other translation and description, in order to have a better and deepened comprehension of the information.

\section{ACKNOWLEDGEMENTS}

The authors would like to thank Dr. Donatella Caporusso, Director of the Archaeological Museum of Milan and Dr Anna Provenzali of the Archaeological Museum for giving the 
possibility to use the 3D models and Dr Sabrina Ceruti for her priceless work and help on the transliteration and translation of the hieroglyphs.

\section{REFERENCES}

Bruno, F., Bruno, S., De Sensi, G., Lughi, M.L., Mancuso, S., Muzzupappa, M., 2010. From 3D reconstruction to virtual reality: a complete methodology for digital archaeological exhibition. Journal of Cultural Heritage 11 (2010) pp. 42-49

Carrozzino, M., Bergamasco, M., 2010. Beyond virtual museums: Experiencing immersive virtual reality in real museums, Journal of Cultural Heritage 11 (2010) pp. 452 458

Cirilli, V., 2013. Hypercolumna. An Archaeological hub for a new way to do culture, XVIII Congreso Internacional Arqueologìa Clàsica, Mérida, 13-17 maggio 2013

Cruz-Neira, C., Sandin, D.J., Defanti T.A., Kenyon R.V., Hart, J.C., 1992. The Cave: audio visual experience automatic virtual environment, Communications of the ACM, Volume 35 Issue 6, June 1992 pp. 64-72

El-Razaz, Z., 2007. VR for Cultural Heritage Valorization: a Comunication problem, Proceedings of Electronic Imaging \& The Visual arts, pp. 146-151

Gallo, L., De Pietro, G., Marra, I., 2008. 3D interaction with volumetric medical data: experiencing the wiimote, Proc. Of the $1^{\text {st }}$ Int. Conf. on ambient Media and Systems, ser. Ambi-Sys, pp 14:1-14:6

Guidi, G., Gonizzi Barsanti, S., Micoli, L.L., Russo, M., 2015. 'Massive 3D Digitization of Museum Contents', in Toniolo, L., M. Boriani, and G. Guidi (eds), Built Heritage: Monitoring Conservation Management Research for Development 2015, pp 335-346

Gutierrez, D., Seron F.J., Magallon, J.A, Sobreviela, E.J., Latorre, P.,2004. Archaeological and cultural heritage: bringing life to an unearthed Muslim suburb in an immersive environment, Journal of cultural heritage 5 (2004) 63-74.

Hirose, M., 2006. Virtual Reality Technology and Museum Exhibit, International journal of virtual reality 5 (2006) 31-36.

Lee, H., Tateyama, Y., Ogi, T., 2010. Realistic visual environment for immersive projection display system, in Virtual System and Multimedia (VSMM), $201016^{\text {th }}$ International Conferenceon, 2010, pp. 128-132.

Loizides, F., El Kater, A., Terlikas, C., Lanitis, A., Michael, D., 2014. Presenting Cypriot Cultural Heritage in Virtual Reality: A User Evaluation M. Ioannides et al. (Eds.), EuroMed 2014, LNCS 8740, pp. 572-579

Pescarin, S., 2014. Virtual reality and cyberarchaeology virtual museums. 3D Recording and Modelling in Archaeology and Cultural Heritage. Remondino F., Campana S. (eds) Theory and best practices, BAR International Series 2598 pp. 129-136

Pietroni, E., Ray, C., Rufa, C., Pletinckx, D., Van Kampen, I., 2012. Natural Interaction in VR Environments for Cultural
Heritage and its Impact Inside Museums: the Etruscanninng Project. Virtual System and Multimedia (VSMM), $201218^{\text {th }}$ International Conference on, 2012, pp. 339-346

Reffat, R.M., Nofal, E.M., 2013. Effective Communication with Cultural Heritage using Virtual Technologies, International Archives of the Photogrammetry, Remote Sensing and Spatial Information Sciences, Volume XL-5/W2, 2013, Interantional CIPA Symposium, 2-6 September 2013, Strasbourg, France, pp. $519-524$

Richards-Rissetto, H., Robertsson, J., von Schwerin, J., Agugiaro, G., Remondino, F., Girardi, G., Forte, M., 2012. Hands-Off: using Kinect to virtually query the ancient Maya city of Copan, Honduras. CAA Conference, 26-30 March, Southampton, UK

Roussou, M., Pujol, L., Katifori, A., Chrysanthi, A., Perry, S., Vayanou, M., 2015. The museum as digital storyteller: Collaborative participatory creation of interactive digital experiences. MW2015: Museums and the Web 2015. Published January 31, 2015. Consulted July 13, 2015. http://mw2015.museumsandtheweb.com/paper/the-museum-asdigital-storyteller-collaborative-participatory-creation-ofinteractive-digital-experiences/

Vayanou, M., Karvounis, M., Kyriakidi, M., Katifori, A., Manola, N., Roussou, M., Ioannidis, Y., 2012. Towards Personalized Storytelling for Museum Visits. 6th International Workshop on Personalized Access, Profile Management, and Context Awareness in Databases (PersDB 2012). Istanbul, Turkey. 